\title{
Age Barriers in Healthcare
}

\author{
Rachel Horton*
}

\begin{abstract}
Age limits, minimum and maximum, and both explicit and 'covert', are still used in the National Health Service to determine access to a range of health interventions, including infertility services and cancer screening and treatment. Evidence suggests that chronological age is used as a proxy for a host of characteristics in determining access to healthcare: as a proxy for the capacity of an individual to benefit from an intervention; for the type of harm that may result from an intervention; for the likelihood of such benefit or harm occurring; and, in some cases, for other indicators used to determine what may be in the patient's interest. Age is used as a proxy in this way in making decisions about both individual patients and wider populations; it may be used where no better 'marker' for the relevant characteristic exists or - for reasons including cost, practicality or fairness - in preference to other available markers. This article reviews the justifications for using age in this way in the context of the existing legal framework on age discrimination in the provision of public services.
\end{abstract}

Keywords: age discrimination, age equality, health care

\section{Introduction}

Over the past few decades there has been a significant reduction in the use of age limits as explicit barriers to access medical treatment, medication or other healthcare services in the UK. Thus, for example, while a 1991 study found 19\% of coronary care units used explicit age-related admissions criteria, by 2001 this had fallen to less than 1\%. ${ }^{1}$ By 2009 , a review commissioned by the Department of Health found very few remaining policies that explicitly determined access on the basis of age. $^{2}$ Nonetheless, uses of age to determine access do remain. This article explores the compatibility of some of these remaining age barriers with UK anti-discrimination law, which has prohibited age discrimination in the provision of public services, including healthcare, since 2012.

Lecturer University of Reading.

1. Centre for Policy on Ageing, Ageism and Age Discrimination in Secondary Health Care in the United Kingdom (2009). This reduction in the use of age can be attributed, at least in part, to the introduction of the (non-legally binding) National Service Framework for Older People, in 2001, which included 'rooting out age discrimination' as the first of its eight standards: Department of Health, National Service Framework for Older People (2001).

2. I. Carruthers and J. Ormondroyd, Achieving Age Equality in Health and Social Care: A Report to the Secretary of State for Health (2009).
The article is organised into two halves. The first half identifies some of the ways in which age is used directly or indirectly - to organise access to medical intervention and treatment, and, as far as is possible, discusses the reasons age is used in this way. The second half assesses whether, and under what conditions, these uses of age may be permitted within the existing legal framework and considers how commissioners and service providers may best ensure that age is used in ways that are compatible with the law. For this reason the focus will be on practices that those involved in the provision of healthcare may plausibly wish to justify. Although there is also ample evidence of other forms of age discrimination in healthcare - including widely publicised accounts of neglect - these are not considered here.

As a preliminary note, it is important to bear in mind throughout that the use of age to organise and limit access to services takes place in the context of a publicly funded health care system with limited resources. It should also be pointed out that, in most cases rationing decisions are taken at the local rather than national level. Policies determining access to treatment are normally developed at the local level by Clinical Commissioning Groups (CCGs) although non-binding guidance is set by the National Institute for Health and Care Excellence (NICE.) In some cases - and particularly in relation to public health programmes such as vaccination and screening - parameters for access are set nationally. The implications of both of these issues for the question of legal justification are discussed in what follows.

\section{Uses of Age to Determine Access to Medical Intervention}

\subsection{Quality Adjusted Life Years (QALYs)}

QALYs are a measure used to calculate the cost-effectiveness of a particular medical intervention. They combine the (health-related) quality of life a patient may expect to have post intervention with their remaining life expectancy. The number of QALYs generated by an intervention can then be combined with the cost of that intervention to create a cost-effectiveness ratio - the cost per QALY. In this way QALYs provide a 'common currency' to allow those with responsibility for resource allocation to compare the costs and benefits of a range of interventions and to set priorities accordingly. QALYs are used to inform decisions about resource allocation by 
NICE, particularly in their evaluation of new and existing health technologies, and are used more widely in research that informs commissioning decisions nationally and locally. ${ }^{3}$

There are several ways in which the use of QALYs in allocating resources may amount to prima facie age discrimination. First, and much discussed in the academic literature, is the fact that given the use of remaining life expectancy in the calculation of the number of QALYs an intervention produces, the method is potentially indirectly discriminatory. Other things being equal, a fifty-year-old will normally produce less QALYs than a thirty-year-old and more than a seventyyear-old. Further, given the increased likelihood of comorbidity (multiple health conditions) in the older patient, their health-related quality of life is likely to be lower pre- and post-intervention. This, also, will serve to reduce the number of QALYs an intervention is capable of producing. ${ }^{4}$ For both of these reasons, the cost per QALY of an intervention for an older patient will often be higher than the cost per QALY of the same intervention for a younger patient. When QALYs are used to inform decisions about which interventions should be funded, and what the access criteria for interventions should be, the methodology has the potential to disadvantage older patients.

This is compounded by concern that the method used to calculate the health-related quality of life may itself be indirectly discriminatory by failing to take into account the experiences and priorities of older patients and overstating the importance of physical functioning. ${ }^{5}$ This may lead to underestimation of quality of life in older people, which, in turn, will impact on the number of QALYs an intervention is capable of generating in an older patient.

For these reasons, then, the use of QALYs to inform resource allocation certainly has the potential to give rise to indirect discrimination on grounds of age. It is argued, however, that while this theoretical potential exists, the context in which QALYs are used in practice - and in particular their use in health technology appraisals by NICE - means that the methodology does not in fact disadvantage older people. ${ }^{6}$ One reason for this is that NICE generally operates at a 'macro' level determining which of a range of possible treatments or interventions are most cost effective for society as whole, rather than at an individual level - determining those members of society who should be eligible for a

3. www.nice.org.uk

4. The same difficulty is also faced by those with pre-existing disabilities whose quality of life score may be lower, post intervention, notwithstanding the success of the intervention itself. See discussion in C. Newdick, Who Should We Treat? Rights, Rationing and Resources in the NHS (2005).

5. A. Hickey et al., 'Measuring Health Related Quality of Life in Older Patient Populations: A Review of Current Approaches', 23(10) Pharmacoeconomics 791-793 (2005); See also R. Edlin et al., Cost Effectiveness Analysis and Ageism: A Review of the Theoretical Literature (2008).

6. A. Stevens et al., 'National Institute for Health and Clinical Excellence Appraisal and Ageism', 38 Journal of Medical Ethics 258-262 (2012). particular treatment. Because of this, it is claimed, it is NICE's normal practice, when evaluating an intervention, to 'assume that what applies to one age group within a particular appraisal will apply inter alia to others'7 and to aggregate the QALYs an intervention produces across a range of ages. Thus, most of NICE's recommendations do not restrict access by age - treatments are generally recommended for all ages or for none and much of the theoretical potential for QALYs to generate discriminatory results is thereby avoided.

This does not eliminate the potential for discrimination altogether, however. While there are very few age-stratified results among NICE's recommendations (where access to a particular intervention is recommended only for a particular age group), some do exist ${ }^{8}$ and it remains the case that interventions that would primarily benefit the older population (rather than society as a whole) are able to produce fewer QALYs (although, so far, there are no examples among NICE's decisions of interventions being turned down for this reason). ${ }^{9}$

\subsection{In Vitro Fertilisation (IVF)}

An example of NICE guidance where recommended access to treatment is determined by age is IVF. Public funding for IVF - at any age - is controversial and raises interesting issues about the boundaries of 'health' and the circumstances in which public funding should be provided to assist individuals and couples to conceive. ${ }^{10}$ In February 2013 NICE published revised guidance on access to IVF and other fertility treatment. ${ }^{11}$ Among other recommendations, the revised guidance suggests that where other clinical criteria are met, women between the ages of forty and forty-two should be eligible for one free cycle of IVF treatment, while women under forty should be offered up to three cycles. Women aged forty-three and over are not eligible for treatment. There is no lower age limit. The previous recommended lower and upper age limits for access to treatment had been twenty-three and thirty-nine. The revised guidance was based on an economic model that used maternal age both as a predictor of the likelihood of success of treatment and (via a QALY analysis) as a proxy for the duration of any improvement in the health state of a couple gained through the IVF treatment.

Local commissioners are not obliged to follow this guidance $^{12}$ and many currently do not. Some CCGs offer no funded IVF treatment at all, and others use different age

\footnotetext{
Ibid.

Ibid. One example - access to IVF - is discussed in more detail later. Edlin, above n. 5, at 72

10. See, e.g. E. McTernan, 'Should Fertility Treatment Be State Funded?', 32(3) Journal of Applied Philosophy 227-240 (2015).

11. National Institute for Health and Clinical Excellence, Fertility: Assessment and Treatment for People with Fertility Problems (February 2013 (updated September 2017), Clinical Guideline 156), https:// www.nice.org.uk/guidance/cg156 (last visited January 2020).

12. NICE technology appraisals are binding on local CCGs. However, CCGs may depart from other forms of NICE Guidance only where they have good reason to do so (see $R$ v. North Derbyshire Health Authority ex parte Fisher, [1997] 8 Med. L R 327 and $R$ (on the application of Rose) v. Thanet Clinical Commissioning Group, [2014] EWHC 1182 (Admin) discussed further below in relation to proportionality).
} 
limits to those recommended by NICE, resulting in what is often termed a postcode lottery. ${ }^{13}$ The decisions of (the then) Berkshire East Primary Care Trust to retain thirty-five as the upper age limit and of (the then) Portsmouth City Primary Care Trust to make thirty the lower age limit for access to IVF treatment were both reported to be subject to possibly the first legal challenges under the age discrimination provisions of the Equality Act 2010. ${ }^{14}$ Since then both CCGs have removed the lower age limit from their assisted conception policies, but have retained thirty-five as the upper age limit for referral for treatment, notwithstanding the NICE recommendations. ${ }^{15}$ The minutes of the Board meeting at which Portsmouth CCG confirmed the upper age limit (among other eligibility criteria) note that the decision was taken as a result of the clinical evidence that the effectiveness of IVF declines after the age of thirty-five and not because of cost. ${ }^{16}$ Elsewhere, lower age limits remain, including, for example, Wiltshire CCG, who currently offer IVF only to women between the ages of thirty and forty. ${ }^{17}$ The lower limit in this case is explained as being based on 'affordability grounds and prioritising treatment for couples where the woman is over thirty five when the success rate of live births begins to decline'. ${ }^{18}$

\subsection{Screening}

Several of the few remaining examples of explicit rationing by age within the NHS relate to national screening programmes. Existing national screening programmes for adults screen for breast, bowel and cervical cancer and for vascular disease. All include both upper and lower age limits for access, although in some cases those outside the age band are able to request screening tests despite being excluded from routine screening invita-

13. Neither Croydon nor Cambridge and Peterborough CCGs currently routinely fund IVF, though this is under review in Cambridge and Peterborough: https://www.croydonccg.nhs.uk/get-involved/public-consul tation-and-engagement/Pages/The-future-of-IVF-services.aspx and https://www.cambridgeshireandpeterboroughccg.nhs.uk/news-andevents/latest-news/statement-on-ivf/ (last visited January 2020).

14. L. Donnelly, 'Couple Sue for IVF in Landmark 'Age Discrimination' case', The Telegraph (London, 1 December 2012), www.telegraph. co.uk/news/health/news/9716432/Couple-sue-for-IVF-in-landmarkage-discrimination-case.html; J. Brown and J. Lawrence, 'Too Young to Have IVF; 24 Year Old Andrea Heywood Fights for Her Right to Fertility Treatment', The Independent (London, 4 June 2012), www.independent.co.uk/life-style/health-and-families/health-news/ too-young-to-have-ivf-24-year-old-andrea-heywood-fights-for-herright-to-fertility-treatment-7814790.html (last visited January 2020).

15. SHIP 8 Clinical Commissioning Groups' Priorities Committee (Southampton, Hampshire, Isle of Wight and Portsmouth CCGs), Policy Recommendation 002: Assisted Conception Services (September 2014), www.portsmouthccg.nhs.uk; NHS South, Central and West Commissioning Support Unit, Berkshire East, Policy Statement 11g: Assisted Reproduction Services for Infertile Couples (November 2013), www. fundingrequests.cscsu.nhs.uk/berkshire-east/cosmetic-and-othersurgeries-berkshire-east/ (last visited January 2020).

16. Portsmouth $\mathrm{CCG}, \mathrm{Al} 03$ Minutes of Governing Board Meeting of 21 January 2015, 210115, GB180315, item 13, www.portsmouth ccg.nhs.uk/About-Us/march-2015_2.htm (last visited January 2020).

17. www.wiltshireccg.nhs.uk/wp-content/uploads/2013/12/IVFpolicy-2016.09.28.pdf.

18. Ibid tions. ${ }^{19}$ However, where screening is available on request but not by invitation, there is evidence that take-up is much lower.

Women between the ages of fifty and seventy are invited for breast cancer screening every three years. Women over the age of seventy do not receive an invitation for screening but are able to request a mammogram every three years, while those below the age of fifty are able to access screening only after referral by their general practitioner (GP) for specialist intervention, where, for example, family history or other clinical factors suggest this would be beneficial. An extension of this age range to forty-seven to seventy-three is currently being trialled nationwide. ${ }^{20}$ In 2013 the All Party Parliamentary Group on Breast Cancer recommended that the trial be extended to those aged seventy-four to seventy-six and, should take-up in this age group be sufficient, to those aged seventy-seven to seventy-nine in a second phase. ${ }^{21}$ However, in 2015, a follow-up report expressed disappointment that these recommendations had not been implemented and that while Public Health England remained supportive in principle, as did healthcare professionals, funding remained an issue. ${ }^{22}$

Bowel Cancer Screening is offered every two years to those between the ages of sixty and seventy-four and a new test is currently being introduced for men and women between fifty-five and sixty with plans to reduce the lower age limit to fifty in time. ${ }^{23}$ Cervical cancer screening is currently offered to women between the ages of twenty-five and sixty-five, or beyond for those who have a history of abnormality or who have never been screened. ${ }^{24}$ The vascular screening programme is now available to those between forty and seventy-four. ${ }^{25}$ In addition to these uses of age limits for access to screening, it is also worth noting that the UK National Screening Committee does not currently recommend prostate cancer screening. ${ }^{26}$ While this clearly applies to all age groups, and thus does not involve any direct discrimination, prostate cancer is a disease that is particularly prevalent in older men, and thus the decision not to provide a national screening programme for this particular cancer is an example of potential indirect discrimination. It is not easy to find clear explanations for the use of age limits in each case - or of the particu-

19. There is some minor variation in the upper and lower age limits in England, Scotland, Wales and Northern Ireland - the age limits given later are those that apply in England. Seewww.cancerscreening.nhs.uk.

20. Ibid.

21. All Party Parliamentary Group on Breast Cancer, Age is Just a Number: The Report of the Parliamentary Inquiry into Older Age and Breast Cancer (2013).

22. All Party Parliamentary Group on Breast Cancer, Two Years On: Age is Just Still a Number: Progress Report on the All Party Parliamentary Group on Breast Cancer's Enquiry into Older Age and Breast Cancer (2015).

23. https://www.nhs.uk/conditions/bowel-cancer-screening/ (last visited January 2020).

24. www.cancerscreening.nhs.uk/cervical/about-cervical-screening.html (last visited January 2020).

25. www.nhs.uk/Conditions/nhs-health-check/Pages/NHS-HealthCheck.aspx (last visited January 2020).

26. www.cancerscreening.nhs.uk/prostate/ (last visited January 2020). 
lar age limits used - in the available public policy materials. However, what follows attempts to summarise the reasons that are provided.

First, the upper and lower age limits chosen may reflect the evidence on the incidence of the relevant disease in particular age groups. Chronological age is used as a proxy for the likelihood of an individual developing the condition the screening programme is intended to detect. The national cancer screening website suggests that the incidence of the disease is the reason for the upper age limit for cervical cancer screening - 'Generally speaking, the natural history and progression of cervical cancer means it is highly unlikely that women of 65 and over will go on to develop the disease. ${ }^{27}$

Second, even where evidence suggests that those in a particular age group may be at risk of developing the condition, screening tests may be unavailable because of evidence that the screening test itself is likely to be ineffective in that age group owing to the changes in the body associated with changes in age. This appears particularly relevant in the case of cervical and breast cancer, where the lower age limits are both justified by reference to the inability of existing screening tests to generate reliable results in particular age groups. ${ }^{28}$

Third, and related, there is concern that, in certain age groups, the risks and disadvantages of the screening tests may outweigh the benefits. There is a concern both that 'false positives' (more likely to be generated by screening in age groups where the screening test is less reliable) may increase anxiety and lead to unnecessary and potentially harmful treatment and that 'true positives' may likewise result in avoidable anxiety and intervention where the age of the patient and the normal progression of the disease mean that the disease would be unlikely to manifest itself naturally during the lifetime of the patient. Thus, a review of the lower age limit for cervical cancer concluded that extending testing to women below the age of twenty-five could lead to adverse psychological impacts and to an increase in unnecessary treatment, which in turn could have harmful side effects in relation to future childbearing. ${ }^{29}$ Similarly, for both bowel ${ }^{30}$ and prostate ${ }^{31}$ cancer screening it has been argued that, given that most older patients in whom screening would detect cancer are likely to die of something else before the cancer reaches its advanced stages, the negative impacts of screening in older age outweigh the benefits.

27. www.cancerscreening.nhs.uk/cervical/faqs.html (last visited January 2020).

28. www.cancerscreening.nhs.uk/breastscreen/faqs.html (last visited January 2020).

29. Minutes of the Advisory Committee on Cervical Screening, 19 May 2009, https://webarchive.nationalarchives.gov.uk/20150505172923/ http://www.cancerscreening.nhs.uk/cervical/cervical-reviewminutes-20090519.pdf (last visited January 2020).

30. C. Quarini and M. Gosney, 'Review of Evidence for a Colorectal Cancer Screening Programme in Elderly People', 38(5) Age and Ageing 503-508 (2009).

31. D. Burford et al., Prostate Cancer Risk Management Programme; Information for Primary Care: PSA Testing in Asymptomatic Men: Evidence Document (NHS Cancer Screening Programmes) (2010).
Fourthly, it has been argued, at least in relation to cervical cancer screening, that using age as the entry point into the screening programme, rather than determining when screening is appropriate for an individual patient based on other factors, ensures that the system is fair, consistent and workable. There was a real danger of stigmatising women if the first screen was to be based on sexual activity or smoking - lifestyle-based risk factors that would, in fact, be the best indicator for when the first cervical screen would be beneficial. ${ }^{32}$

Finally, there is cost-effectiveness. The national screening programmes do not come under the auspices of NICE guidance, and there is no clear explanation of how cost-effectiveness is determined in relation to the various screening programmes or of how information on cost-effectiveness is then used in decision-making in relation to age limits. Clearly, many of the other reasons discussed previously are relevant to cost-effectiveness. Research on cost-effectiveness is certainly evident in research that informs the decisions about the ages at which the various screening programmes should be offered. Thus, in relation to the lower age limit for vascular screening, and upper and lower age limits for breast cancer screening, QALYs were used to model the cost-effectiveness of a range of lower age limits. ${ }^{33}$

\subsection{Mental Health Services}

Age discrimination in mental health services has been the subject of recent research and political focus. Weaknesses in mental health provision are particularly likely to affect the older population: $30 \%$ of mental health inpatients are aged over sixty-five. ${ }^{34}$ It is clear that some of the failures in provision of mental health services in the older population are the result of ageist stereotypes or misconceptions - a view of mental health problems such as depression or dementia as a 'normal' part of ageing, for example. ${ }^{35}$ However, an important cause is normally identified as stemming from the segregation of mental health service provision for working age and older adults; in many (though not all) localities, mental health services are divided into 'adult mental health' for adults up to the age of (usually) 65 and 'older people's mental health' for those over sixty-five. ${ }^{36}$ While this division was originally intended to offer better and specialised services to those in different age groups, reflect-

32. Minutes of the Advisory Committee on Cervical Screening, above n. 29, at 7.2 .

33. Department of Health, Putting Prevention First - Vascular Checks: Risk Assessment and Management (2008); A. Rawdin and J. Madan, An Initial Assessment of the Merits of Extending Breast Cancer Screening Aged 47-49 Years to Assist the Appraisal of Options for Extending the NHSBSP with Appendix Considering Women Aged 71-73 (2008).

34. Healthcare Commission, Count Me in 2008: Results of the 2008 National Census of Inpatients in Mental Health and Learning Disability Services in England and Wales (2008).

35. Centre for Policy on Ageing, above n. 1. Royal College of Psychiatrists, Suffering in Silence: Age Inequality in Older People's Mental Health Care (College Report 221) (2018).

36. Ibid. Mental health provision for children and adolescents is also organised as separate services but will not be discussed here. Under-18s are not covered by the age discrimination provisions of the Equality Act 2010. 
ing the (often) different health needs of each group, the implementation of the segregated services is generally agreed to have resulted in poorer services for the older group. In 2009, a consultation by the Government Equalities Office found that in some trusts older people were unable to access services that were available to younger adults. ${ }^{37}$ Thus, while working age adults in some areas are able to access services such as crisis care, out of hours and occupational health, older adults are not. ${ }^{38}$ For some patients this means that once they reach sixty-five they are transferred from the care of adult mental health to older people's mental health services and thereby excluded from services from which they had previously benefited. These - among other - features of the difference in service provision have led some commentators to conclude that 'mental health services in the NHS provide one of the few remaining examples, in many localities, of overt, institutional direct age discrimination'. ${ }^{39}$

However, while most agree that current divergence in the quality and quantity of service provision is unacceptable, there is debate over whether the solution lies in integrated or segregated-but-better services. One reason for the initial segregation of services was that the profile of mental health problems in the working age and the older populations is significantly different. In particular, as adults reach later life, there is a decline in the prevalence of psychoses and a rise in dementia, with dementia accounting for over one-third of hospital mental health patients aged sixty-five and over, and over half of those aged seventy-five and over. ${ }^{40}$ Further, according to the Royal College of Psychiatrists, older people may develop mental health problems related to social and lifestyle changes brought about by ageing, which require a specialised response. ${ }^{41}$ Age is therefore agreed to be a good proxy for mental health needs.

The different mental health needs that may arise in the older population have led to calls to retain - but improve - separate service provision for older people. Indeed, there is a concern that failure to do so could itself amount to (indirect) age discrimination by failing to recognise and respond appropriately to the needs of the older population. Thus, the Department of Health, following a consultation on this issue, concluded that specialist older people's mental health services should continue because the ageing population has particular needs; many adult mental health services are designed to meet the needs of working age adults with severe mental health problems and would fail to meet the needs of older adults with different conditions. The conclusion was that what was needed were specialist services of equiva-

37. Government Equalities Office, Equality Bill: Making It Work. Ending Age Discrimination in Services and Public Functions - A Consultation (2009)

38. Centre for Policy on Ageing, above n. 1.

39. Ibid.

40. Ibid.

41. Royal College of Psychiatrists, above n. 35. lent quality. ${ }^{42}$ Similarly, the Royal College of Psychiatrists, while arguing that an arbitrary age limit should not be used to determine the services a person is entitled to receive, were clear that age-appropriate mental age services should be retained:

it is unacceptable to offer a single, age inclusive mental health service that is not designed to meet the need of older people and to do so would be discrimination. ${ }^{43}$

Solutions have been suggested and, in some places, implemented that attempt to retain age-appropriate services without using chronological age as the (only) criterion for determining access. These include formal agreements between working age and older adult mental health services that provide - for example - for reassessment of mental health needs at 65 , rather than automatic transfer. ${ }^{44}$ However, it appears that there is no consensus on whether older people's mental health services should be organised as a separate service. ${ }^{45}$

\subsection{Non-overt Discrimination}

The previous sections have assessed some of the few remaining examples of explicit age differentiation in access to services. In addition to these examples of explicit use as age as a criterion for access to services, there is evidence that age serves as a factor in determining whether and which services to offer in a wide range of situations involving individual clinical judgment. Age appears to affect preventative care, the likelihood of investigation and referral and the type of care and treatment subsequently available, across a range of specialities.

A clear example is in the case of cancer services. Most cancers are more prevalent in later life. Over half of all cancers diagnosed are in people aged sixty-five or over; a third of all cancers diagnosed are in those aged seventy-five or over. ${ }^{46}$ Despite this age profile, however, a 2012 study by the Department of Health concluded that there is a marked decline in referral for more 'intensive' treatment - including surgical intervention - as patient age increases. Thus, for example, the incidence of breast cancer peaks in the 85-plus age group, but surgical intervention for breast cancer declines sharply after the age of seventy. ${ }^{47}$ This is despite the relevant NICE guideline, which is explicit that surgical intervention should be offered regardless of chronological age. ${ }^{48}$ The

42. Department of Health, New Horizons: Towards a Shared Vision for Mental Health - A Consultation (2009)

43. Royal College of Psychiatrists, Age Discrimination in Mental Health Services: Making Equality a Reality (position statement PS2/2009) (2009)

44. Centre for Policy on Ageing, above n. 1.

45. Ibid.

46. Department of Health, The Impact of Patient Age on Clinical Decision Making in Oncology (2012). See also Royal College of Surgeons, Access All Ages: Assessing the Impact of Age on Access to Surgical Treatments (2013).

47. Ibid. Department of Health.

48. National Institute for Health and Clinical Excellence, Clinical Guidance for Early and Locally Advanced Breast Cancer (CG80) (2009). 
low rate of surgical intervention is thought to be one of the reasons cancer outcomes in those over the age of seventy-five may be poorer in the UK than in other comparable countries. The study concluded that, in making decisions about access to oncology services, and, in particular, in determining the level of intensity of the treatment that should be provided 'clinicians may over rely on chronological age as a proxy for other factors which are often but not necessarily associated with age, such as comorbidities or frailty'. ${ }^{49}$ Similar patterns emerge in respect of other service, including cardiology, stroke and mental health. ${ }^{50}$

Clinical assessment of a patient on the basis of chronological age - rather than on the basis of actual frailty, comorbidity and polypharmacy - may, of course, involve unwarranted 'ageist' judgments such as, for example, mistaken assumptions about the preferences or lifestyle needs of an individual patient. It may also involve the use of chronological age as a proxy for the risks and harms a course of treatment may produce in an individual patient where, for example, there is a strong statistical correlation between age and risk and no reliable test for assessing biological age. ${ }^{51}$ There is relatively little research on the ways in which age is used by individual clinicians, but that which there is suggests that chronological age may be used as a proxy for a number of indicators, including risk or capacity to benefit. Thus, for example, some clinicians participating in a study of the influence of patient age on decision-making on coronary care noted that a patient's chronological age may influence their views on whether to refer them for surgery as it served as a proxy for the risk of mortality or the development of complications. Some clinicians in the same study also used patient age as a marker for wider concerns about what may be in the patient's best interests. One, for example, noted that 'they wouldn't want an angiogram if they were over 70'; another, that 'I don't think bypass surgery in an 87 year old is in their interests'. 52

\subsection{Summary}

The foregoing review suggests that chronological age is used as a proxy for a host of characteristics in determining access to treatment: as a proxy for the capacity of an individual to benefit from an intervention; for the type of harm that may result from an intervention; for the likelihood of such benefit or harm occurring; and, in some cases, for other indicators used to determine what may be in the patient's interest. Age is used as a proxy in this way in making decisions about both individual patients and wider populations; it may be used where no

49. Department of Health, above n. 46

50. Royal College of Surgeons, above n. 46; Royal College of Psychiatrists, above n. 35.

51. See e.g. Department of Health, above note 46, which suggests that the lack of an objective way of assessing biological age in some contexts may lead to clinicians using chronological age as a proxy.

52. C. Harries et al., 'Which Doctors are Influenced by a Patient's Age? A Multi Method Study of Angina Treatment in General Practice, Cardiology and Gerontology', 16 Quality and Safety in Health Care 23-27 (2007). better 'marker' for the relevant characteristic exists or where - for reasons including cost, practicality or fairness - age may be used in preference to other available markers. The next section now considers how these reasons for using age may fit with existing anti-discrimination law.

\section{Legislative Framework}

Under the Equality Act, service providers must not discriminate directly or indirectly on grounds of age. However, they may adopt measures that would otherwise amount to direct or indirect age discrimination if they can show that the measure in question is a 'proportionate means of achieving a legitimate aim. ${ }^{53}$

There have, as yet, been no reported cases on age discrimination in the provision of healthcare. In order to understand the way the justification may operate in this context, therefore, we must look to other case law for guidance on the likely approach to be taken by the courts on the scope of the test for justification. A number of sources are likely to be particularly helpful.

The first is the case law on age discrimination in employment where a significant body of case law has emerged both in the UK and in the European Court of Justice (CJEU). There has been some judicial consideration of whether the meaning of discrimination, and the approach to interpretation to be taken by the Court, should be the same across the various areas of life regulated by anti-discrimination law. Thus, by way of example, the House of Lords, in the disability discrimination case of Lemisham v. Malcolm, concluded that the test for establishing 'disability related discrimination' must mean the same in relation to housing and to employment, despite the different overall scheme of the different sections of the (then) Disability Discrimination Act $1995 .{ }^{54}$ Likewise, in Elias, a case concerning indirect race discrimination the administration of a government compensation scheme for prisoners of war, it was held that the appropriate test of proportionality under the 1976 Race Relations Act was that developed by the CJEU in Bilka in the context of a claim of sex discrimination in the workplace, even though the claim in Elias was not one to which EU anti-discrimination law applied. ${ }^{55}$ There is therefore good reason to think that the approach developed to justification in the case law on age discrimination in employment, both in the UK Courts and in the CJEU, will inform the approach taken to discrimination in healthcare.

A second useful source is case law on discrimination in public services, both under the Equality Act 2010 (where, again, case law is very limited) and under Article 14 of the European Convention on Human Rights (ECHR.) The ECHR has not proved fruitful territory in

\footnotetext{
53. Sections 13 and 19

54. Malcolm v. Lewisham LBC, [2008] UKHL 43.

55. $R$. (on the application of Elias) v. Secretary of State for Defence, [2006] EWCA Civ 1293.
} 
establishing a positive right to healthcare treatment the European Court of Human Rights (ECtHR) having confirmed in Senteges and in Pentiacova ${ }^{56}$ that Article 8 is generally not engaged in situations that involve a decision not to provide a particular form of treatment. Indeed in the UK case of Condliff the Court of Appeal noted that

[a]lthough the Strasbourg Court has recognised that in principle Article 8 may be relied on to impose a positive obligation on a state to take measures to provide support for an individual, including medical support, there is no reported case in which the court has upheld such a claim by an individual complaining of the state's non-provision of medical treatment. ${ }^{57}$

As a result, there is very little that can be said with confidence about the obligations of healthcare providers in relation to Article 14, and the implications for the interpretation of the Equality Act. Nonetheless, ECHR case law will be instructive in relation to approaches to age discrimination and to the bounds of permissible justification in relation to the provision of public services and the allocation of scarce resources.

The situation is further complicated by the fact that courts have often tended to treat age differently from other protected grounds of discrimination and to engage in lighter touch review of justification in consequence. ${ }^{58}$ Thus, for example, in consideration of Gurkha pensions entitlements in the Court of Appeal, Kay LJ decided that 'stronger justification' would be required for discrimination on grounds of nationality than it was on grounds of age. Nationality was a suspect ground, whereas age was not. Arguments by the counsel for the appellants that age should be given 'suspect' status because 'it is innate, unalterable, closely connected with personal development and central to a person's individuality' were rejected as unsupported by domestic or Strasbourg authority. ${ }^{59}$ In Carson age was identified as a 'contemporary example of a borderline case' between these two categories of 'suspect' and 'non-suspect' characteristics. ${ }^{60}$ It is therefore difficult to be confident in assessing the extent to which judicial reasoning on other grounds of discrimination will be relevant to cases on age.

With those caveats in mind, the next two sections will assess the way the test for justification may apply to the instances of potential age discrimination identified previously - first, by considering whether the aims given

56. Sentges v. Netherlands, [2004] 7 CCL Rep 400; Pentiacova v. Moldova, [2005] 40 EHRR SE23.

57. $R$ (on the application of Condliff) v. North Staffordshire Primary Care Trust, [2011] EWCA Civ 910, at 41

58. For discussion see R. Horton, 'Justifying Age Discrimination in the EU', in U. Belavusau and K. Henrard (eds.), EU Anti-Discrimination Law Beyond Gender (2018) and S. Goosey, 'Is Age Discrimination a Less Serious Form of Discrimination?', Legal Studies 1-17 (2019).

59. $R$ (British Gurkha Welfare Society and Others) v. Ministry of Defence, [2010] EWCA Civ 1098, at 11.

60. $R$ (on the application of Carson) v. Secretary of State for Work and Pensions and $R$ (on the application of Reynolds) v. Secretary of State for Work and Pensions, [2006] 1 AC 173. for the uses of age are likely to be 'legitimate' and, second, by assessing whether using age boundaries is likely to be a proportionate means to achieve them.

\subsection{Legitimate Aims}

\subsubsection{Cost-effectiveness}

Behind many decisions to restrict access to health interventions, however this is done, is of course the need to ration limited resources. The use of age to determine access is no different. It was seen earlier that behind the restriction on IVF services and screening programmes by age, and indeed the design of the QALY methodolo$\mathrm{gy}$, is a desire to allocate resources cost-effectively.

In a public law context, as Herring notes, challenges to healthcare rationing decisions in the UK are rarely successful: courts are unwilling to intervene where issues of resource allocation are concerned unless manifestly irrational. ${ }^{61}$ Where judicial review succeeds it tends to be on procedural grounds rather than because a refusal of any particular treatment is substantively unfair. This is the case even where the treatment involved is potentially life-saving. ${ }^{62}$ Where challenges have succeeded they have tended to involve procedural failures such as, for example, a failure to adequately define what would constitute an exceptionality in relation to the refusal to provide an expensive cancer $\operatorname{drug}^{63}$ or a policy that allowed no room for the exercise of discretion and consideration of individual facts in relation to gender reassignment surgery ${ }^{64}$ - matters that, in a discrimination law context would more likely fall to be determined under the question of proportionate means, discussed later.

Is the approach of the courts likely to be any different when considering justification of age discrimination under the Equality Act? We know that in an employment law context, cost saving, without more, is unlikely to amount to legitimate aim - employers may not engage in discriminatory behaviour simply because it is cheaper to do so. However, courts have treated aims expressed in terms of prudent use of resources more sympathetically. Thus, while the Court of Appeal in Woodcock agreed that 'considerations based on cost alone, or on economic or financial factors alone, cannot justify treatment that is discriminatory on grounds of age', ${ }^{65}$ subsequent cases have noted that it is 'legitimate for an organisation to seek to break even year on year and to make decisions about the allocation of its resources'. ${ }^{66}$ The CJEU has made similar comments. ${ }^{67}$

61. J. Herring, Medical Law and Ethics (2012). See also Newdick, above n. 4; C. Foster, 'Simple Rationality? The Law of Healthcare Resource Allocation in England', 33 Journal of Medical Ethics 404-407 (2007).

62. $R$ v. Cambridge Health Authority ex parte B, [1995] 2 All ER 129, CA.

63. $R$ (on the application of Rogers) v. Swindon NHS Primary Care Trust and another, [2006] EWCA Civ 392.

64. $R$ v. North West Lancashire Health Authority, ex p A, D \& G, [2001] 1 WLR 977.

65. Woodcock v. Cumbria PCT, [2012] EWCA Civ 330, at 55.

66. See, most recently Heskett v. Secretary of State for Justice, [2019] UKEAT/0149/18/DA, at 25.

67. See Case C159/10 Fuchs and another v. Land Hessen, [2011] 3 CMLR 47 
Against this background, then, it is difficult to imagine courts challenging the aims of targeting scarce resources most efficiently to those most likely to benefit. Any challenge is more likely to arise in relation to the means chosen to do so.

\subsubsection{Protection of Patients}

More difficult, perhaps, are those aims, identified previously, that aim to protect patients from some form of distress. It will be remembered that these kinds of reasons featured in the justification for the upper and lower ages for access to screening, where decision makers expressed a preference to shield patients from the distress of 'false positives' or of 'true positives' where the progress of the disease meant individuals were likely to die of something else before the cancer became fatal. There was also a desire to protect young women from the stigma of invitations to screening for cervical cancer based on lifestyle. Reasoning based on the assumed wishes or interests of older patients was also evident in the limited evidence available on the ways in which clinicians may use age in deciding on the most appropriate treatment pathway.

The UK Supreme Court did accept an - arguably comparable reason as a legitimate aim in $\operatorname{Seldon}^{68}$ following the guidance of the CJEU. Mr Seldon, a solicitor and partner in the respondent law firm, had been required to retire from the partnership at the age of sixty-five. The respondent firm claimed that their treatment of Mr Seldon was justified by a number of aims, one of which was to limit the need to expel partners by way of performance management, thus contributing to a congenial and supportive culture in the respondent firm. By the time the case reached the Supreme Court, this aim was expressed in terms of a concern for preserving the dignity of the individual partner or employee by avoiding potentially humiliating performance management and disputes about competence. The Supreme Court was unanimous that this aim, among others, was legitimate and indeed had been held to be so by the CJEU.

This decision (and this feature of it in particular) have proved controversial, not least because it rests on assumptions about what older people may want and who is best placed to decide this. ${ }^{69}$ While avoiding performance management and disputes is likely to be in the interests of the employer, the aim was also expressed as being to ensure the best outcome for employees. Thus, it seemed to reinforce a stereotype of older people as being not only more vulnerable to potentially humiliating capability proceedings and in need of protection from them but also as not best placed to choose for themselves whether or not to remain in the workplace and to risk a capability assessment at some point in the future. Age UK, intervening in Seldon, had argued that the dignity of each individual was the philosophy under- lying all the anti-discrimination laws and that this amounted to a right not to be treated on the basis of stereotypical assumptions. Dignity included respect for the autonomy. ${ }^{70}$ Lady Hale expressed some sympathy with this position, but she concluded that the CJEU's acceptance of dispute avoidance/preserving dignity as a legitimate aim was the end of the matter.

While there is reason, therefore, to believe such aims may be considered legitimate, they are perhaps more vulnerable to challenge. This may be particularly the case in relation to decision-making by clinicians in respect of individual patients. In related areas of law regulating the doctor-patient relationship, such as informed consent, there has been, in recent years, a marked move away from 'medical paternalism' and towards patient autonomy; doctors may not withhold information from patients for fear of causing them distress unless in exceptional circumstances and may certainly not do so in order to prevent 'the patient from making an informed choice... which the doctor considers to be contrary to her best interests' ${ }^{71}$

\subsubsection{Meeting the Needs of Different Groups}

In relation to mental health services, it is evident from the foregoing discussion that there is an ongoing debate over whether age-specialist services are appropriate and indeed whether a failure to provide age-specialised services may create disadvantage to older patients such as to amount to indirect discrimination.

Targeting services to particular groups in order to meet need is very likely to amount to a legitimate aim. In respect of other characteristics - where no justification for what may otherwise amount to direct discrimination is permitted - the Equality Act includes exceptions that permit different treatment in specified circumstances. For example, the provision of separate services to different sexes is permitted where it can be shown that a joint service would be less effective and the provision amounts to a proportionate means of achieving a legitimate aim. The positive action provisions of the Act also permit different treatment for groups sharing a protected characteristic where it is shown that the aim of the treatment is to meet the needs of the relevant group or to overcome disadvantage connected to the characteristic and the treatment is a proportionate means of achieving that aim.

In relation to age discrimination in employment, both the CJEU and the UK courts have been happy to accept as legitimate aims that relate to redressing disadvantage faced by particular age groups in the labour market and/or improving intergenerational equity.

There seems little doubt, therefore, that an objective of improving services for a particular age group will be legitimate and the provision of age-specialised services will be justified provided the means of achieving the aim are proportionate. 


\subsection{Proportionality}

Once a legitimate aim has been established as a first step, the test for proportionality, although not always applied wholly consistently, ${ }^{72}$ tends to consist of three further steps. Second and third - as drawn from the case law of the CJEU going back to Bilka - are the questions of whether the chosen measure is appropriate for achieving the chosen objective and no more than necessary to accomplish it. However, as recently noted by Lady Hale,

[t]he concept of proportionality, which has found its way into both the law of the European Union and the European Convention on Human Rights, has always contained a fourth element. This is the importance, at the end of the exercise, of the overall balance between the ends and the means: there are some situations in which the ends, however meritorious, cannot justify the only means which is capable of achieving them. ${ }^{73}$

This section assesses whether it is possible to identify a number of features that case law suggests may be relevant to determining whether and when the use of age as a proxy criterion in accessing healthcare intervention is proportionate. These features are the accuracy of the proxy and - related - the impact on those excluded; the availability of an alternative - less discriminatory - test; and whether there is scope for considering whether an exception to a rule should be made in the case of a particular individual.

\subsubsection{Accuracy}

Courts have rejected the use of some protected characteristics, including sex and race, as proxies, even where their use has been statistically well evidenced. In Test Achats, for example, the use of sex as a proxy for risk in calculating motor insurance premiums was rejected even though this could be substantiated by accurate actuarial and statistical data. ${ }^{74}$ In relation to age, however, courts have appeared far more prepared to accept the use of age as a proxy, in principle at least. In these cases the question of the accuracy of the proxy then becomes potentially relevant to the question of proportionality. Accuracy should matter in proportionality assessment. The less accurate the proxy, the more people are likely to be on the 'wrong side' of the line and excluded from access to the benefit in question. Along with the nature of any hardship caused - which will also depend on the nature of the benefit to which access is denied - the accuracy of the proxy will be one of the considerations relevant to balancing the aim of the measure against the impact on those affected.

72. A. Baker, 'Proportionality and Employment Discrimination in the UK', 37(4) Industrial Law Journal 305-328 (2008).

73. Akerman-Livingstone v. Aster Communities Ltd, [2015] UKSC 15, at 28.

74. Case C-236/09 Association Belge des Consommateurs Test-Achats ASBL and Others v. Conseil des ministres, [2011] 5 CMLR 36; see also Timishev v. Russia, [2007] 44 EHRR 37 on the use of race as a proxy.
The CJEU has been prepared to challenge the accuracy of the use of age as a proxy in a number of cases. ${ }^{75} \mathrm{In}$ Hennigs the Court found the use of an age-gradated pay scheme to be unjustified. It rejected the argument that older workers had greater financial needs than younger workers, noting that

it has not been shown that there is a direct correlation between the age of employees and their financial needs. Thus a young employee may have substantial family burdens to bear while an older employee may be unmarried without dependant children. ${ }^{76}$

Presumably, had a direct correlation been established, the Court would have taken a different view. In Prigge the Court was asked to consider a rule in a collective agreement requiring compulsory retirement of airline pilots at sixty, where age was used as a proxy for a decline in the physical capacities needed to perform the role safely. ${ }^{77}$ While not challenging the argument that age can stand as a proxy for physical capacity, the Court found the choice of sixty to be disproportionate in this case because there was no evidence to support it. National and international legislation permitted pilots to continue working in certain circumstances until sixtyfive, and no evidence had been provided to justify a departure from this standard.

Evidence aside, the use of age as a proxy in relation to health is always going to present difficulties with regard to accuracy in relation to health for at least two reasons. First, there is a widely acknowledged difference between 'chronological age' and 'biological age.' Grimley Evans has argued that chronological age does not serve as an accurate proxy for health-related risks or capacity to benefit, because there can be wide variance between the chronological age of an individual and their biological age; and because even though there may be correlation between age and health, age is not the cause of anything:

We have grown so inured to using a patient's age as an excuse for laziness in investigating him or her properly that we have failed to build into our scientific paradigms proper identification of the true physiological determinants of outcome... If one knows enough about the physiological condition of the patient, age should drop off the end of the predictive equation for outcome. ${ }^{78}$

Second, even where chronological age does serve as a good proxy for some other characteristic, it is difficult to imagine that it can ever adequately capture all and only those having that characteristic, because, as the House

75. However not consistently so. See, for example Kucukdeveci v. Swedex $\mathrm{GmbH} \&$ Co KG, [2010] 2 CMLR 33.

76. C-297/10 Hennigs v. Eisenbahn-Bundesamtat, [2012] 1 CMLR 18, at 70.

77. C-447/09 Prigge v. Deutsche Lufthansa AG EU:C:2011:573.

78. J. Grimley Evans, 'Age Discrimination: Implications of the Ageing Process', in S. Fredman and S. Spencer (eds.), Age as an Equality Issue (2003), at 19-20. 
of Lords accepted in Carson and Reynolds, 'there could be no relevant difference between a person the day before and the day after his or her birthday'. ${ }^{79}$ In that case the House of Lords considered whether a provision restricting certain social security benefits to those under the age of twenty-five was in breach of Article 14 of the ECHR. Finding that the use of age was a relevant proxy for financial need (the government had argued that many more under twenty-fives lived with their families or in shared accommodation and therefore had lower expenses), the Court accepted that the choice of any particular age here could only ever be an 'arbitrary line'. However, it was argued,

[A] line must be drawn somewhere. All that is necessary is that it should reflect a difference between the substantial majority of the people on either side of the line. ${ }^{80}$

In relation to the examples of the use of age, above, there is certainly cause for concern about the accuracy of the age limits chosen in some cases. A review of the literature on the use of age in access to screening programmes concluded that

while some (screening programmes) have a sound evidence base and for others there is no available evidence, some are clearly discriminatory and are not justifiable by disease prevalence or any other clinical indicator. $^{81}$

Thus, for example, while the upper age limit for vascular screening is currently seventy-four, most strokes occur in those aged seventy-five or over, and therefore it is important to monitor hypertension in this age group too; ${ }^{82}$ and the upper age limit for cervical cancer screening is explained - as noted previously - as reflecting the fact that those over sixty-five are 'highly unlikely to go on to develop the disease', whereas research suggests that more women in their seventies die from cervical cancer than women under thirty and that there is a second 'peak' in the incidence of cervical cancer in those over the age of eighty-five. ${ }^{83}$ Thus, the proportionality of the choice of the current age limits certainly seem open to challenge for this reason.

It is also interesting to consider how this might apply in relation to the 'postcode lottery' for access to IVF services. It was seen that different age limits for access are used by different CCGs and that many depart in this respect from the guidance on age limits issued by NICE. In respect of their public law obligations, it was held in Rose v. Thanet that while CCGs are not obliged to follow NICE guidance, they must have regard to them and must provide clear reasons for departing from them.

79. $R$ (on the application of Carson), [2006] 1 AC 173, at 41.

80. Ibid.

81. Centre for Policy on Ageing, above n. 1, at 22.

82. G. Xavier, 'The New Health Checks Must Not Be Allowed to Increase Inequalities', 105(14) Nursing Times 9 (2009).

83. C. White, 'Upper Age Limit Should be Raised for Cancer Screening', 318 British Medical Journal 831 (1999); www.cancerresearchuk.org.
Notably, it was held that they will be in breach of their public law obligations should they depart from the guidance solely on the basis of disagreement with NICE over the current state of medical science. A similar obligation could be argued to exist in relation to justifying the choice of a particular age limit for IVF. It was seen that in Prigge a departure from internationally accepted age limit for pilots, without good reason, was a reason for finding the relevant measure disproportionate. Likewise, given NICE's conclusions on the effectiveness of IVF in particular age groups, CCGs may be argued to be acting disproportionately, taking a different view on this issue and choosing different age limits accordingly. A choice of different age limits should therefore be justified by reference to other reasons relevant to local needs and priorities.

\subsubsection{Availability of Less Discriminatory Measure}

Given that a measure must be 'necessary' in order to be proportionate, the existence of a less discriminatory alternative to the use of a particular age limit may signal that the measure in question is not proportionate. An alternative measure may include using a different criterion (which may include, for age, a different age limit), testing each individual to see whether those concerned do indeed possess the necessary characteristics to qualify for whatever benefit is at stake, or asking individuals about their preferences.

The CJEU has not been consistent in its approach to this issue. There was no suggestion, for example, in Petersen, that the use of age to determine when a dentist was no longer safe to practise was disproportionate because it could have been replaced by an individual fitness to practise test, administered to all dentists. ${ }^{84}$ However, in Vital Perez the CJEU took a different view in considering a measure that set a maximum recruitment age of thirty for a local Spanish police force in order to guarantee a certain level of physical capacity among recruits. ${ }^{85}$ The Court rejected the measure as disproportionate because the use of an age limit to achieve the aim here was unnecessary - the police force already used stringent physical tests as part of the recruitment process. This made the use of the age limit unnecessary to establish the aim and therefore disproportionate.

In relation to Article 14, it has been suggested that 'necessity' is neither necessary nor sufficient but instead is simply one of the 'tools of analysis in examining the cogency of the reasons put forward in justification of a measure'. ${ }^{86}$ At least in relation to non-suspect categories, it seems, the existence of a less discriminatory alternative does not mean a measure will fail the proportionality test; and the administrative workability and cost of alternatives are certainly relevant. Bibi, for example, concerned the application of a language test to applicants for long-term residence. Nationality was used

84. C-341/08 Petersen v. Berufungsausschuss fur Zahnarzte fur den Bezirk Westfalen-Lippe, [2010] 2 CMLR 31.

85. C-416/13 Vital Perez v. Ayuntamiento de Oviedo EU C:2014:2109

86. $R$ (on the application of Wilson) v. Wychavon DC, [2007] EWCA Civ 52. 
as a proxy to determine who should be exempt from the test and who should not - nationals from English-speaking countries were exempt. The possibility of an alternative approach, including individual testing, was considered. The Court held that

it would be absurd to suggest that a person should have to undergo a test to prove that he or she meets the language requirement in order that he or she should be entitled to benefit from an exemption from the requirement to undergo a language test... in this context, it is administratively sensible and permissible to draw relatively 'broad' or 'bright' lines in terms of selecting those who can be considered as already sufficiently meeting the requirement to justify being exempted from the provision. What is necessary is that the particular 'bright line' adopted be a rational one. ${ }^{87}$

Likewise, even where a feasible alternative test is conceivable, the cost and administrative inconvenience involved may incline the Court to decide that a failure to choose the alternative was not disproportionate. ${ }^{88}$

Interestingly, in Seldon, age was used as a proxy, among other things, for declining capacity. The argument was that the mandatory retirement age in question was justified as a means of preserving the dignity of older workers by preventing their dismissal for incapacity. There was a notable and somewhat frustrating lack of discussion on this issue in the case, which makes conclusions harder to draw. However, it was accepted that age should be used as a proxy for declining capacity in order to avoid an actual capacity test. The purpose of the age limit was to protect individuals from this assumed humiliation. Thus, the nature of the alternative test was deemed a reason to find the measure proportionate.

The theoretical possibility of testing each individual rather than applying an age limit is therefore unlikely to be enough to make the use of an age limit disproportionate. Rather, the cost and workability of administering individual testing will be relevant to a determination of proportionality - particularly where, it is imagined, the legitimate aim in question involves the efficient targeting of scarce resources. Thus, for example, in relation to cancer screening, analogous with Bibi, if screening cannot be available to everybody then the use of individual testing to determine access to screening makes little sense. However, in cases where individual assessment does not incur significant costs or present other significant difficulties - and in particular, where individual assessment is already undertaken (as was the case in Vital Perez) - then a case might be made that the imposition of age limits is unnecessary and therefore disproportionate. This is likely to be the case in relation to the use of age by individual clinicians. Chronological age may be a useful starting point, in some cases, for diagnosis or choice of treatment pathway. However, clinicians should have the opportunity to assess, in some respects at least, whether what may generally be true of patients of a particular age is in fact true for the patient in front of them. So too, in relation to the division of mental health provision into age group-specialised services, there seems no reason why, in most cases, choice of the most appropriate service for the particular patient cannot be assessed by the referring clinician or (in the case of transfer between services) the existing care team. Indeed this is the approach recommended by the Joint Commissioning Panel for Mental Health, which notes that older people should not be precluded from accessing services provided for working age adults where assessment of their needs indicates that this would be appropriate..$^{89}$

\subsubsection{Exceptionality}

Another potentially important - and closely related consideration is that of exceptionality. Given that proportionality requires a balancing between the aim of a measure and the impact on those disadvantaged by it, the possibility of making exceptions to a general rule for individuals who can demonstrate a good reason for doing so means that the harmful impacts of the rule may be reduced.

A concern for making exceptions has not been evident in the cases considering the justification of age limits in employment law. Indeed in Seldon the Supreme Court was asked to decide whether, in addition to having to justify a general rule that discriminated directly on grounds of age, an employer had to justify the application of that rule to the particular applicant. The applicant argued that even if the use of the mandatory retirement age was in general a proportionate means of achieving a legitimate aim, its application to him could not be justified. The Court held, however, that 'where it is justified to have a general rule, then the existence of that rule will usually justify the treatment which results from it'. Requiring employers to justify the application of rules to individual employees would, it was argued, normally negate the value of having a rule in the first place. ${ }^{90}$

The possibility of an exception being made has, however, been a relevant consideration in determining proportionality under Article 14 of the ECHR. In AL (Serbia), for example, it was one of the features that led the Court to conclude that the government policy of using family status to determine eligibility for indefinite leave to remain was justified. The measure was proportionate because, among other things, it permitted compelling
87. $R$ (Bibi) v. Secretary of State for the Home Department, [2013] EWCA Civ 322, at 42 citing J. Beatson, at first instance, [2011] EWHC 3370 (Admin), at 132.

88. $R$ (on the application of Hooper) v. Secretary of State for Work and Pensions, [2002] EWHC 191 (Admin).
89. Joint Commissioning Panel for Mental Health, Guidance for Commissioners of Older People's Mental Health Services (May 2013), www.jcpmh.info (last visited July 2019)

90. Above n. 67, at 65 and 66 . 
claims by those falling outside the policy to be recognised and accommodated'. ${ }^{91}$

The relationship between exceptionality and proportionality - and how these considerations may be applied to the use of age barriers for access to healthcare therefore remains unclear. It seems at least that, while not a requirement of proportionality, the existence of an opportunity for individuals to make a case for being an exception to the rule may be a relevant consideration in any balancing exercise.

As public bodies, healthcare commissioners are already under a public law duty not to fetter their discretion through the strict application of a blanket rule $(R \mathrm{v}$. North West Lancashire Health Authority, exp A, D E G, [2001] 1 WLR 977). Rather, they are obliged to have some mechanism whereby exceptions to the rule can be made for patients who can demonstrate exceptional circumstances. Accordingly, CCGs operate a system whereby individuals who do not otherwise qualify for a particular intervention my submit an individual funding request (IFR) to seek treatment on the basis of exceptionality where they do not otherwise qualify for treatment. Although there remains a lack of clear legal guidance on what may amount to exceptional circumstances ${ }^{92}$ commissioners tend to restrict these to clinical factors only.

It is not known whether there have been IFRs that have succeeded because an individual patient has shown that they have exceptional circumstances in relation to an age limit. ${ }^{93}$ It is not clear whether evidence showing that - for example - the biological age of the patient is significantly different from their chronological age in relevant respects would be sufficient to demonstrate exceptionality. If so, it may provide an opportunity for women denied IVF because of age to demonstrate that, as is sometimes the case, their biological ovarian age differs significantly from their chronological age.

In relation to screening services, it was seen that, in some circumstances, screening may be available to those not in the age group routinely invited, either where they are able to self refer, or where a GP may refer on the basis that the risk is higher for them than for others of their age. While there is evidence that the take-up of self-referral is low, in part because individuals may not be aware of the option, these opportunities - at least if adequately publicised - may again mitigate the impact of the use of age limits and render their use more proportionate as a result.

\section{Conclusion}

This article has aimed to assess, as far as is possible, the compatibility of some uses of age in the allocation of healthcare with the existing legal framework. It was seen that age is still used as a proxy for a range of factors, including need, risk and capacity to benefit. The analysis suggests that, in most cases, these uses of age may be legally justifiable. However, it suggests, in order to ensure that the use of age is proportionate, that care should be taken to ensure that it is evidence based and as accurate as possible, is used consistently and is only used where the opportunity for individual assessment is unworkable. It is also important that meaningful provision exists for individuals to make a case for accessing the healthcare in question even when they fall on the wrong side of a limit.

Perhaps the most legally questionable example of the use of age discussed previously is where clinicians use it to determine treatment pathways for individual patients. This may not be compatible with the law where it is done for 'paternalistic' reasons and where, because of the opportunity for assessment of and discussion with the individual patient, the use of a patient's chronological age to determine access to treatment is less likely to be proportionate. Further research to understand more about when - and how - individual clinicians use chronological age in decision-making would be welcome, not least because it would help determine whether the correlation identified between age and treatment offered is in part a result of unlawful age discrimination.

91. AL (Serbia) v. Secretary of State for the Home Department, [2008] UKHL 42, at 3; See also $R$ v. Entry Clearance Office ex parte AbuGidary, [2000] 2000 WL 741931 QBD.

92. A. Ford, 'The Concept of Exceptionality: A Legal Farce?', 20 Medical Law Review 304-336 (2012).

93. There has been one case reported in the press, but the basis of the successful appeal was not reported. https://www.telegraph.co.uk/women/ womens-health/8965796/Couple-win-IVF-funding-battle-withNHS.html. See $R$ v. Sheffield HA ex parte Searle, [1995] 25 BMLR 1 pre Equality Act 2010 - where a judicial review challenge to the application of an age limit for IVF services and refusal to consider each case on an individual basis, failed. 